\title{
EPENDIMOMA DE CAUDA EQUINA COM METASTASES A DISTANCIA
}

\author{
SONIA MARIA LIMA:
}

Os ependimomas, tumores mais frequentes em crianças e adultos jovens, originam-se das células ependimárias e podem surgir em qualquer lugar onde existam essas células ${ }^{4}$. No encéfalo esses tumores ocupam o segundo lugar em ordem de frequência dos tumores de origem glial, e são ultrapassados apenas pelos astrocitomas, sendo a localização mais frequente o assoalho do IV ventrículo 2,3 . Entretanto, na cauda equina, é o tipo de glioma mais frequente.

$\mathrm{Na}$ classificação desses tumores, dois critérios são seguidos: um baseado no grau de diferenciação que indica o potencial de malignidade; o outro, baseado no aspecto histológico, compreende quatro tipos (epitelial, celular, papilífero ou mixopapilífero e papiloma do plexo coróide) ${ }^{5}$, ${ }^{4}$.

\section{OBSERVAÇAO}

M.J.S. (Reg. n." 64.498), sexo feminino, de cor parda, com 1 ano e 4 meses de idade, apresentava uma tumoração volumosa na região sacro-coccigea, que comprimia o períneo, com sinais de compressão venosa, evidenciado pelo edema da vulva e membros inferiores (Fig. 1). A tumoração era fixa e dolorosa à palpacão. Os gânglios inguinais esquerdos apresentavam-se hipertrofiados e a pele a este nivel exibia áreas de necrose (Fig. 1). Havia hipotonia muscular com evidente paraparesia e diminuição dos reflexos profundos, notadamente à esquerda. A paciente permaneceu internada durante um mês. Neste periodo foram realizados um exame radiológico que não permitiu diagnóstico conclusivo e uma biópsia da tumoração, cujo diagnóstico foi de ependimoma tipo papilifero, grau III.

Exame pós-morte - A tumoração ocupava a regiāo sacro-coccígea, destruía o osso e infiltrava os tecidos moles; entretanto, não se evidenciou infiltração do tumor na cavidade pélvica. O tumor exibia uma coloração branco-amarelada, consistência amolecida com áreas císticas contendo liquido viscoso e algumas áreas de necrose. Os linfonodos inguinais esquerdos achavam-se comprometidos pela tumoracão. $O$ fígado exibia pequeno nódulo (Fig. 2) que, ao corte, mostrava uma coloração branco-amarelada; nos pulmões existiam nódulos de igual aspecto, além de bronco-pneumonia que foi a causa morte da paciente. Não havia comprometimento da medula espinhal e do encéfalo.

Trabalho apresentado no V Congresso Regional Centro-Iseste de Patologia, em Brasilia - D.F., em setembro de 1973: * Auxilar de Ensino de Patologia Geral na Universidade Federal de Sergipe e patologista da Fundacãa dé Beneficênciá Hospistal de Cirurgia em Aracaju (SE). 

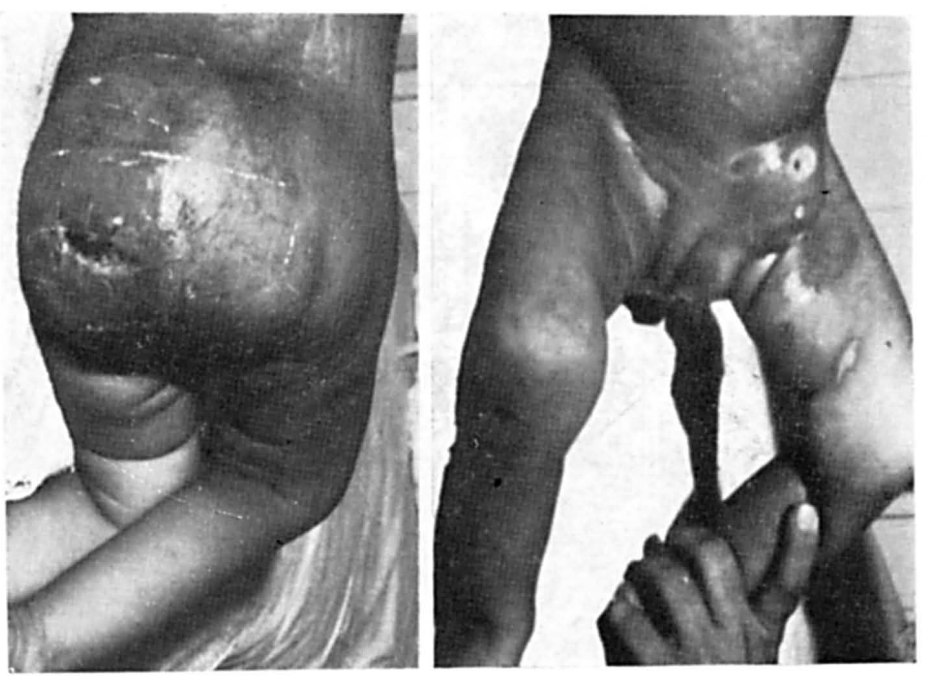

Fig. 1 - Caso M.J.S. Aspecto externo da tumoracĩo onde se observa o comprometimento da região sacro-coccigea e a área de onde foi retirada a biónsia; comprometimento dos linfonodos inguinais pelo crescimento secundário do tumor.

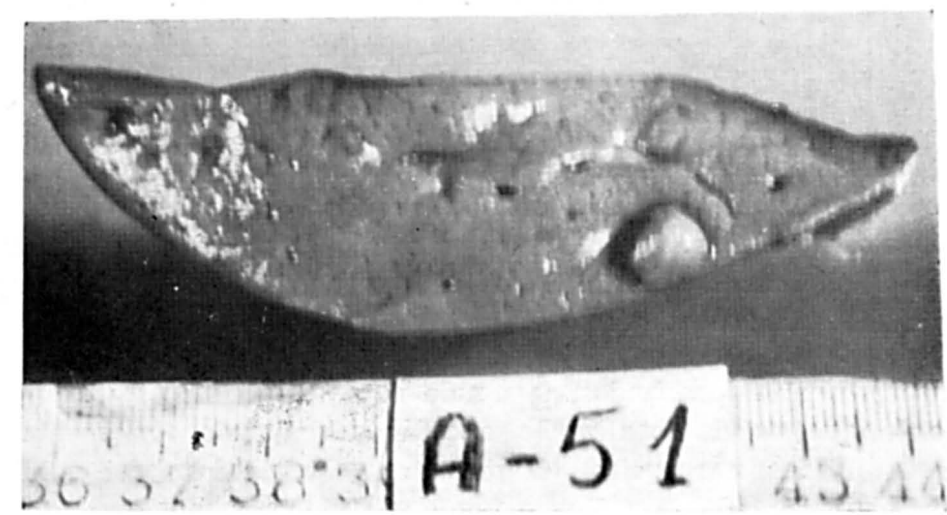

Fig. z-Caso M.J.S. Superficie de corte do figado com o nódulo metastático.

Ao exame histológico, secsōes do tumor (Fig. 3) mostravam áreas de aspecto papilifero. com um eixo conjuntico ricamente vascularizado, recoherto por células com um aspecto morfológico variado, algumas cilindricas, outras cúbicas, exibindo núcleo vesiculoso de tamanho variado, algumas ‘om nucléolo evidenté. Em algumas áreas do tumor observou-se que as células neoplásicas exibindo processos citoplasmáticos se dispunham em torno de rasos sanguineos. Fm outras áreas as células 'm (amadia únic'a formaram estruturas tubulares lembrando o ranal ependimárin) () estroma em algumas áreas mostrava aspecto mixomatoso. Ilavia também (x- 
tensas áreas de necrose. Os tumores secundários exibiam aspecto semelhante ao do tumor primitivo.
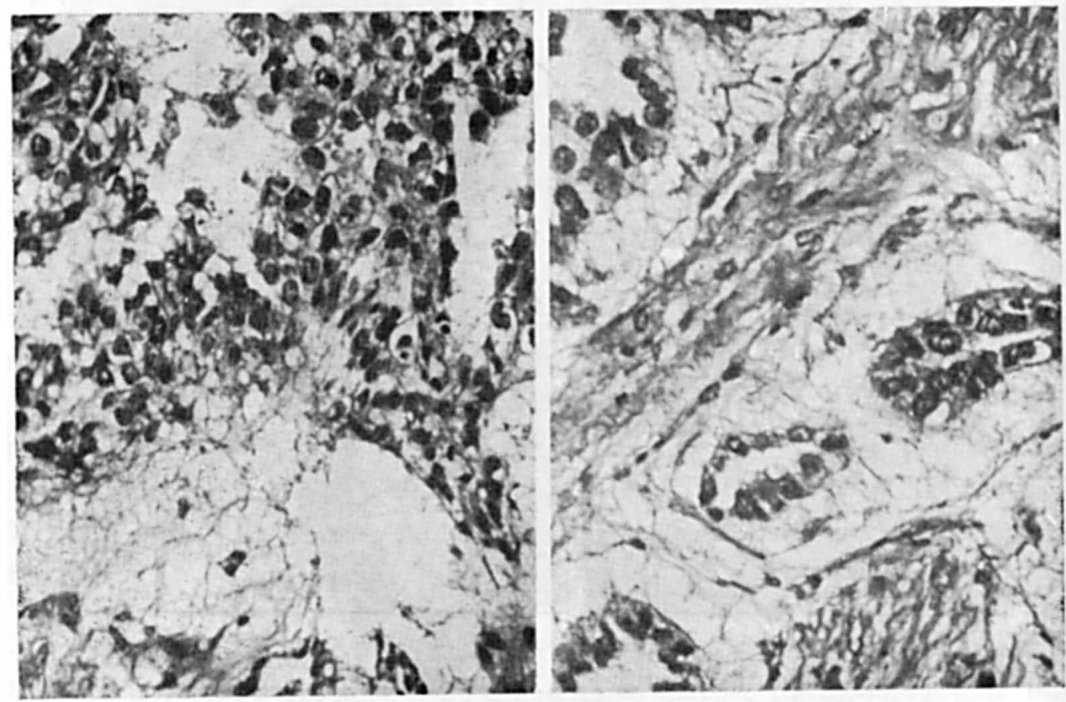

Fig. 3 -.- Aspecio hisło!ógico do tumor: à esquerda se observa a variacion do tamanho nuclear e o arranjo papilffero das células; à direita secção em área onde se observam estruturas tubulares lembrando o canal ependimário. (H. E. $400 x)$.

\section{DISCUSSÃO}

Os gliomas raramente dão metástases fora do sistema nervoso central (SNC) e os ependimomas dão metástase com menos frequência que os outros tipos de gliomas. O primeiro caso de ependimoma com metástase for'a do SNC foi descrito em 1952 por Mastrogostino, citado por Fragoyannis \& Yalcin ${ }^{3}$, em paciente do sexo masculino.

Os ependimomas localizados na cauda equina dão metástases menos frequentemente que os de localização encefálica, havendo um menor número de casos publicados a respeito. O primeiro caso descrito foi publicado em 1955, por Weiss, citado por Fragoyannis \& Yalcin ", em paciente do sexo masculino, com metástase para vários órgãos; seguiram-se ulteriormente mais cinco casos, sendo assinalados em todos eles metástases para o fígado e pulmāo::. :. ‘. Os pacientes eram adultos jovens, entre 17 e 29 anos de idade, havendo apenas um caso de uma criança com $2^{1 / 2}$ anos de idade. Foi assinalada incidência quase igual em ambos os sexos (Tabela 1). Histologicamente, os tumores eram do tipo papilífero, com exceção de um caso que foi do tipo mixopapilífero; entretanto, para alguns autores, esse tipo representa apenas uma variação do primeiro, caracterizado por áreas de degeneração mixomatosa do estroma. 


\begin{tabular}{|c|c|c|c|c|c|}
\hline Autor & Ano & $\begin{array}{l}\text { Idade } e \\
\text { do paci }\end{array}$ & $\begin{array}{l}\text { sexo } \\
\text { nte }\end{array}$ & Localizacão das metástases & Tipos de tumor \\
\hline Weiss & 1965 & 224 & M & $\begin{array}{l}\text { Retroperitôneo, figado, parede do tórax, pleura, pulmōes me- } \\
\text { diastino, linfonodos tráqueo-bronquiais. }\end{array}$ & Papilifero \\
\hline Sharma & 1956 & $29 a$ & $\mathbf{M}$ & $\begin{array}{l}\text { Mediastino, subcutâneo sobre o esterno, pulmões, pleura, fí- } \\
\text { gado. }\end{array}$ & Mixopapilifero \\
\hline Patterson \& col. & 1961 & $28 \mathbf{a}$ & $\mathbf{F}$ & $\begin{array}{l}\text { Mediastino, pleura, pulmão, figado, linfonodos hilares e pa- } \\
\text { ra-aórticos. }\end{array}$ & Papilifero \\
\hline Satodate \& col. & 1967 & $2 \mathrm{a} / 6 \mathrm{~m}$ & $\mathrm{~F}$ & $\begin{array}{l}\text { Figado, timo, puImões, vértebras, músculos para-vertebrais, } \\
\text { pelvis, linfonodos retroperitoniais, inguinais, mediastinais. }\end{array}$ & Papilifero \\
\hline Rubstein \& Logan & 1970 & $17 a$ & $\mathrm{~F}$ & $\begin{array}{l}\text { Pulmões, pleura, linfonodos para-aórticos, parede do IV ven- } \\
\text { triculo. }\end{array}$ & Papilifero \\
\hline Barone \& Elvidge & 1970 & 一 & - & Linfonodos retroperitoniais, pulmōes e figado. & - \\
\hline Presente comunic:acão & 1975 & $1 \mathrm{a} / 4 \mathrm{~m}$ & $F$ & Linfonodos inguinais, figado, pulmões. & Papilifero \\
\hline
\end{tabular}

Tabela 1 - Casos de ependiomas da cauda equina com metástases à distância. 
Não se conhecem as razōes pelas quais esses tumores dão metástases com tão pouca frequência; alguns autores procuram explicar o fato como sendo uma resposta inibitória dos outros tecidos do corpo do hospedeiio ao crescimento das células tumorais originadas no sistema nervoso central".

Os ependimomas podem originar-se também em situação extra-dural, no tecido subcutâneo da região sacro-coccigea e sua origem é explicada, pela maioria dos autores, a partir de restos embrionários; geralmente estão associados a espina bífida. Anderson ${ }^{1}$ descreveu 7 casos de ependimoma localizađos nessa região e há, na literatura, duas publicações a respeito de ependimomas extra-durais na região coccigea, com metástase à distância 4 , ".

A presente publicação registra na literatura brasileira o primeiro caso de ependimoma da região sacro-coccígea com metástases fora do SNC. Não foi possivel estabelecer a origem topográfica do tumor, se intra ou extra-dural, cm decorrência da extensão da tumoração; entretanto, julgou-se de origem intra-dural em virtude de ser esta a localização mais frequente. As localizações das metástases coincidiram com os demais casos publicados na literatura.

\section{RESUMO}

E relatado um caso de ependimoma da cauda equina com metástases fora do sistema nervoso central, em uma criança do sexo feminino, com 1 ano e 4 meses de idade, confirmado mediante exame necroscópico completo. As metástases se localizaram no fígado, nos pulmões e em linfonodos inguinais. Os ependimomas representam o tipo de glioma mais frequente nessa região; entretanto, esses tumores dão metástases muito raramente. Revisando a literatura foram encontrados seis casos.

\section{SUMMARY}

Ependymomu of the cauda equina with distant metastases: (t) case report with review of the literature

A case of a papillary ependymoma of the spinal cord (cauda equina । with metastatic dissemination outside the central nervous system is reported. The patient was a one year old female child who died of pulmonary infection. Metastases were found in the liver, lungs and inguinal lymph nodes. Ependymoma is the most frequent type of glioma found in the cauda equina but metastatic dissemination is a rare occurrence. Only six cases have been recorded in the literature.

\section{REFERENCIAS}

1. ANDERSON, M. S. - Myxopappilary ependymomas presenting in the solt tissut over the sacrococ'ygeal region. Cancer 19:585, 1966. 
2. FORKES, E. C. \& EARLY, K. M. - Ependymomas: rlinical and pathologic'al aspects. J. Neurosurg. 30:585, 1969.

3. FRAGOYANNIS, S. \& YALCIN, S. - Ependymomas with distant metastases: report of two rases and review of the literature. Cancer 19:246, 1966.

4. HENDREN, T. H. \& HARIN, C. A. - Extradural metastatic ependymoma. Surgery $54: 880,1963$.

5. KERNOHAN, J. W. - Ependymomas. In Jeff Minckler - Pathology of the Nervous System. Mc Graw-Hill, New York, 1972.

6. KERNOHAN, J. W. \& SAYRE, G. P. - Ependymomas. Armed Forces Institute of Pathology. Section X, Fasc. 35 and 37, Washington DC, 1952.

7. PATTERSON JR., R. H. \& CAMPBELL JR., W. G. - Ependymoma of the cauda equina with multiple visceral metastases. Cancer 30:145, 1972.

8. RUBSTEIN, L. J. \& LOGAN, W. J. - Extraneural metastases in ependymomia of the cauda equina. J. Neurol. Neurosurg. Psychiat. 33:763, 1970.

9. WOLF, M.; HECTOR, S. \& DUBY, M. M. - Delayed distant metastases from a sacrococcigeal ependymoma: case report, with tissue culture, ultra-structural observations and review of the literature. Cancer 30:1046, 1972.

Departamento de Patologia - Hospital Prof. Edgar Santos - y000o Salvado!. $B A$ - Brasil. 